\title{
Multidisciplinary Interventions in Motor Neuron Disease
}

\author{
U. E. Williams, E. E. Philip-Ephraim, and S. K. Oparah \\ Internal Medicine Department, University of Calabar, Calabar, Cross River State 540242, Nigeria \\ Correspondence should be addressed to U. E. Williams; williamsuduak@yahoo.co.uk
}

Received 20 June 2014; Revised 29 September 2014; Accepted 28 October 2014; Published 18 November 2014

Academic Editor: Anabela C. Pinto

Copyright (C) 2014 U. E. Williams et al. This is an open access article distributed under the Creative Commons Attribution License, which permits unrestricted use, distribution, and reproduction in any medium, provided the original work is properly cited.

\begin{abstract}
Motor neuron disease is a neurodegenerative disease characterized by loss of upper motor neuron in the motor cortex and lower motor neurons in the brain stem and spinal cord. Death occurs 2-4 years after the onset of the disease. A complex interplay of cellular processes such as mitochondrial dysfunction, oxidative stress, excitotoxicity, and impaired axonal transport are proposed pathogenetic processes underlying neuronal cell loss. Currently evidence exists for the use of riluzole as a disease modifying drug; multidisciplinary team care approach to patient management; noninvasive ventilation for respiratory management; botulinum toxin B for sialorrhoea treatment; palliative care throughout the course of the disease; and Modafinil use for fatigue treatment. Further research is needed in management of dysphagia, bronchial secretion, pseudobulbar affect, spasticity, cramps, insomnia, cognitive impairment, and communication in motor neuron disease.
\end{abstract}

\section{Background}

Motor neuron disease (MND) also referred to as amyotrophic lateral sclerosis (ALS) is a fatal neurodegenerative condition with an annual incidence of about 1.5 per 100,000 [1] and a United Kingdom (UK) prevalence of 4-6/100,000 [2]. There is a slight male preponderance with a male to female ratio of $3: 2$. It could occur at any age but the peak age of occurrence is between 50 and 75 years [3].

Multiple genetic and environmental factors interact resulting in loss of the upper motor neuron in the motor cortex and the lower motor neurons cell bodies in the brain stem and spinal cord $[4,5]$. Pattern of onset could be spinal, truncal, or bulbar. The clinical features of MND include limb weakness, respiratory impairment, dysphagia, fatigue, sleep disorders, pain, psychosocial distress, communication deficits, cognitive impairment, and spasticity. Death occurs secondary to respiratory failure 2 to 4 years after disease onset on average; however survival of patients up to a decade has been reported [6]. There is currently no cure for MND; hence management is focused on symptomatic treatment, rehabilitative care, and palliative care. The disease exerts a huge psychological and economic burden on the patient and caregivers.

\section{Review Strategy}

Evidence for this review was obtained from a search of the Cochrane data base, PUBMED, guidelines of National Institute for Clinical Excellence (NICE), American Academy of Neurology (AAN), and European Federation of Neurological Societies (EFNS); and peer-reviewed journal articles. MND diagnosis is based on the El Escorial diagnostic criteria $[4,5]$.

\section{Objectives}

This review aims to objectively evaluate the role of the multidisciplinary support care available to patients with MND, the evidence basis for intervention modalities, and highlight areas for future research. The benefit(s) of intervention measures are assessed on their impact on outcome measures such as survival, quality of life (QOL), decreased hospitalization, improved 3 disability, and cost effectiveness.

\section{Evidence for Multidisciplinary Care (MDC) Strategies and Modalities}

4.1. Care Setting. MDC approach is the main stay for the management of patients with chronic neurological conditions 
such as multiple sclerosis [7], stroke [8], acquired brain injury [9], and MND. MDC is defined as any care delivered by two or more disciplines [10], involving a neurologist and other allied disciplines such MND nurse, chest physiologist, and occupational therapist. Other personnel needed as part of the MDC team for MND care includes occupational therapists, physiotherapists, social workers, counselors, speech and language therapist, and religious leaders. Care is administered 24 hours daily in a hospital or on outpatient basis or in the patients' home or community, but effort must be effectively coordinated to avoid overlapping or missing care due to the large number of care providers involved in the management of the patient and their family. MDC is important in enabling care specialist to undertake proper assessment of patients and addressing the concerns of patients and family [11, 12].

An Irish prospective population-based cohort study [13] compared 344 patients in MDC to patients in general neurology care (GNC) and found 7.5-month longer survival in the MDC cohort $(P<0.004)$. Another cross-sectional study involving 208 participants with MND [14] observed an improved QOL in patients with MND who attended MND clinic 6-12 weekly compared to participants who attended a 6 -monthly GNC. In a subsequent report [15] observed no difference in healthcare cost between MDC and GNC settings.

In an Italian study involving 126 ALS patients [16], no difference in the median survival time between MDC care and a GNC cohort was reported (17.6 months versus 18 months; $P=0.76$ ). The low riluzole and noninvasive ventilation (NIV) use has been suggested as the reason why there was no difference in survival observed in this study [12]. Another Italian study [17], reviewing 221 participants in a MDC setting, noted an improved median survival $(P=$ 0.008 ), decreased hospitalization (1.2 admission frequency versus $3.3, P=0.003)$, and decreased duration of hospital stay (5.8 versus 12.4 days, $P=0.001$ ) in the MDC cohort.

A group [18] retrospectively reviewed hospital notes of 162 patients seen between 1998 and 2002 in GNC and 255 others managed under MDC care between 2006 and 2010 in a tertiary hospital. Median survival from diagnosis was 19 months for MDC and 11 months for GNC (Hazard ratio $0.51,95 \%$ confidence interval $0.41-0.64$ ). They also analyzed the relationship between MDC and survival independent of riluzole, NIV, and PEG use. Although this study selected patients from multiple neurologists in the region, a rigorous methodology was used to ensure proper patient selection and matching. Other factors that are being suggested as contributing to an improved outcome in MDC setting include better symptomatic support, access to aids, and prompt treatment of respiratory challenges [14]. Both AAN and EFNS recommend MDC care setting for patients with MND, with the current EFNS guidelines recognizing the benefit of MDC approach in improving survival, reducing medical complications, and improving the quality of life of patients and their caregivers $[19,20]$.

4.2. Neuroprotective Treatment and Disease-Modifying Therapy (DMT). The exact molecular pathway leading to the loss of motor neurons in MND remains unclear, but evidence of
TABLE 1: Genetics of MND.

\begin{tabular}{ll}
\hline Type of MND & Genetic mutation \\
& (i) SOD1 gene [100]. \\
& (ii) TDP-43 [101-103]. \\
& (iii) Alsin (ALS2) [104, 105]. \\
Familial MND & (iv) Senataxin (ALS4) [106]. \\
& (v) Vesicle associated membrane-protein \\
& (VAPB, ALS8) [107]. \\
& (vi) Angiogenin [108, 109]. \\
& (vii) Mutation in the p150 subunit of dynactin \\
& (DCTN1) [110, 111]. \\
& Genetic mutations linked to greater \\
& susceptibility to sporadic MND include \\
& (1) apolipoprotein E4, [112] \\
& (2) decreased expression of excitatory amino \\
& acid transporter-2 protein [113, 114], \\
(3) alterations in the vascular endothelial & growth factor (VEGF) gene [115].
\end{tabular}

interplay between complex cellular processes acting synergistically is accumulating [21, 22]. Mutation in super oxide dismutase (SOD1) and TAR-DNA binding protein (TDP43) among others are strong genetic risk factors [21, 23]. A summary of the genetic and pathophysiologic processes in MND is summarized in Tables 1 and 2.

Riluzole is the only registered DMT for MND which slows the disease progression but does not stop the underlying disorder. The mechanism of action of riluzole involves blocking of presynaptic glutamate release [24]. Four trials [25-28] provided the evidence base for riluzole as a DMT. The first controlled trial involving riluzole [25] reported a modest increase survival among treated patients compared to controls receiving placebo. The same group undertook a subsequent study [26] to address some of the issues raised in the pilot study and confirmed that riluzole is well tolerated and it also extends survival of MND patients. The metaanalysis of these studies showed that irrespective of the patient selection, $100 \mathrm{mg}$ prolongs median survival in people with MND by 2-3 months [29]. Minor reversible adverse reactions reported were nausea, asthenia, fatigue, and an increase in liver enzymes. A recent population-based study [16] found a 6-month overall survival benefit that was significant in bulbar onset and elderly patients, but not in patients with a limb-onset disease. No additional benefits were noted when coadministered with add-on such as Vitamin E [30] or Gabapentin [31].

Recombinant human insulin-like growth factor-1 (rhIGF1) has been proposed as a MDT in MND following its ability to promote spinal motor neuron survival after excitatory amino acid induced death in animal models $[32,33]$. A Cochrane review [34] of the benefit of rhIGF-1 on disease progression using 3 studies involving 799 MND patients observed low quality evidence of improved QOL scores at 9 months, with no impact on survival. A meta-analysis of 2 well randomized trials using ciliary neurotrophic factor (CNTF) as a DMT in 1300 MND patients showed no significant 
TABLE 2: Pathophysiological processes in MND.

\begin{tabular}{ll}
\hline Pathophysiologic process & Comments \\
\hline Excitotoxicity & $\begin{array}{l}\text { Excessive postsynaptic glutamate induced stimulation of glutamate receptors such as NMDA \& AMPA } \\
\rightarrow \text { massive calcium influx } \rightarrow \text { nitric acid formation and neuronal death [21, 116]. }\end{array}$ \\
\hline Oxidative stress & $\begin{array}{l}\text { Fibroblast culture from MND patients shows increased sensitivity to oxidative damage. Accumulation of } \\
\text { free oxygen species } \rightarrow \text { cell death. SOD1 is an antioxidant enzyme [116]. }\end{array}$ \\
\hline Mitochondrial defect & $\begin{array}{l}\text { Abnormalities of mitochondrial morphology and biochemistry have been reported in sporadic MND } \\
\text { patients, in SOD1 transgenic mice, and in cellular models [117, 118]. }\end{array}$ \\
\hline $\begin{array}{l}\text { Impaired axonal transport } \\
\text { Neurofilament aggregation }\end{array}$ & $\begin{array}{l}\text { The relatively long length of motor neuron depends on effective transport systems. Evidence of } \\
\text { abnormalities in this transport system has been reported in transgenic mice [119-121]. }\end{array}$ \\
\hline $\begin{array}{l}\text { Abnormal accumulation of neurofilament commonly occurs in many neurodegenerative diseases } \\
\text { including MND [122, 123]. }\end{array}$ \\
\hline $\begin{array}{l}\text { Inflammatory dysfunction } \\
\text { toxic or beneficial to the cell [21, 22]. }\end{array}$ \\
$\begin{array}{l}\text { Deficits in neurotrophic } \\
\text { factors and dysfunction of } \\
\text { signaling pathway }\end{array}$ & $\begin{array}{l}\text { Deficits in levels of neurotrophic factors, e.g., IGF-1, have been reported in MND [124-126]. } \\
\text { Apoptosis }\end{array}$ \\
\hline
\end{tabular}

difference between it and placebo, unlike findings reported in animal models which were favorable [35].

The proposed involvement of free radical accumulation and oxidative stress in MND has informed the trial of antioxidants in MND. A meta-analysis of 10 studies involving 1015 MND patients [36] reported weak evidence for the efficacy of antioxidants in MND. Some of the antioxidants which have had positive effect in animal studies are vitamins $\mathrm{C}$ and E [37], selegiline [38], N-acetylcysteine [39], and dehydroepiandrosterone [40].

\subsection{Symptomatic Management}

4.3.1. Respiratory Management. Respiratory impairment is the leading cause of death in MND. Denervation weakness of respiratory muscles results in ineffective cough, retention of secretion, and hypoventilation, and it is an important determinant of QOL [41-43]. Its proper management can improve survival and QOL [44]. Onset of respiratory impairment is marked by sleep disordered breathing (SDB) which results in early morning headaches, nonrefreshing sleep, daytime somnolence, dyspnea, orthopnea, poor concentration, and fatigue [41]. Assisted ventilation in MND can be provided using invasive technique via tracheostomy or NIV using face or nasal mask.

In a study involving 22 subjects with MND [45], a 2monthly assessment of QOL using Short Form Health Survey (SF-36), chronic respiratory disease questionnaire, sleeps apnoea quality of life index, and respiratory function and a 4-monthly polysomnography showed improvement in sleep related problems and mental health that was maintained for 252 to 458 days. Overall survival was significant between NIV patients and those on standard care. Moderate to severe bulbar weakness was associated with a lower improvement in QOL.
In a subsequent randomized control trial (RCT) [46] involving 22 MND patients on NIV and 19 on standard care, a 48-day longer mean survival in the NIV group was observed compared to the standard care group $(P=0.0062)$ at 12 months. In the subgroup with good to moderate bulbar function survival was 205 days longer $(P=0.0059)$. The strength of this study was the computer-based randomized allocation of patients to respiratory support and the even matching of patients and controls in terms of demographic characteristic and functional ability. This study has documented convincingly that NIV prolongs median survival. A review by NICE has further confirmed the cost effectiveness of NIV used for MND patients [44]. NIV improves gas exchange, alleviates symptoms of carbon dioxide retention, and improved QOL [47]. The exact mechanism of action of NIV is unknown, but it may be related to the reversing of chronic respiratory fatigue, reversing of hypercapnia, resolution of atelectasis, and decreasing of the rate of decline of FVC [48]. Claustrophobia, anxiety, excessive salivation, nasal bridge soreness, and abdominal bloating are some of the problems associated with NIV use in MND patients [41].

The effectiveness of NIV can be enhanced by the use of telemonitoring of NIV. Pinto et al. [49] evaluated home telemonitoring of NIV in ALS patients and observed that there was improved survival and lower office and emergency room visit or admissions among patients who had telemonitoring compared with the control group which who had their compliance and ventilator parameter settings assessed only during clinic visits. They concluded that telemonitoring help reduce health care cost and improve survival and functional status.

Invasive ventilation or tracheostomy ventilation (TV) can also be used to deliver air into the lungs and to clear secretions. It is used in patients with severe bulbar dysfunction who cannot tolerate NIV or in patients previously 
using NIV whose respiratory function has deteriorated to a point where NIV is not tolerated [41]. A retrospective chart review combined with prospective evaluation of QOL and degree of depression [50] obtained a survival rate of $65 \%$ by 1 year and $45 \%$ by 2 years after tracheostomy. Survival was significantly shorter in patients older than 60 years with a hazard ratio of dying of 2.1 ( $95 \%$ confidence interval, 1.1-3.9). While TV allows for suction of secretion and avoids facemask and claustrophobia, it predisposes to recurrent infection, tracheostomy site infection, bleeding, and tracheaoesophageal fistula formation [51]. It is not encouraged in the USA or Europe but it is the most commonly used respiratory support in Japan $[52,53]$.

Respiration can also be assisted using an electrical stimulation of the diaphragm to produce contractions (diaphragmatic pacing). It is a procedure originally meant for patients with cervical spine injury [54], but still experimental in MND. Four electrodes are placed on the motor roots of the phrenic nerves on the abdominal surface of the diaphragm. Thus it is only effective if the diaphragm still retains some innervation [41]. The diaphragmatic pacing in patients with respiratory muscle weakness due to motor neurone diseasestudy (DIPALS) is an ongoing RCT assessing the efficacy of diaphragmatic pacing among MND patients in some UK hospitals.

Apart from hypoventilation, respiratory weakness also impairs cough [55]. Insufficient cough results in recurrent chest infection, which is the leading cause of hospitalization in MND [56]. The strength of the patients' cough is assessed with a peak flow meter and reported as suboptimal if the peak cough-flow (PCF) is less than 270/min [57]. Cough can be augmented using intensive physiotherapy and manoeuvres like tussive squeeze and mechanical in-exsufflator (MI-E). Evidence for MI-E is weak, but it has been suggested that it could be effective in MND patients for cough management $[58,59]$.

4.3.2. Nutritional Management. Dysphagia may occur in MND due to loss of coordination, weakness of muscles of mastication, weakness of tongue, and impaired swallowing. This can be complicated by weight loss, distressing choking, prolonged effortful meal times, frequent aspiration, and increase risk of chest infection [60-62]. Malnutrition positively correlates with a shortened survival rate and is a poor prognostic factor [63]. Management of dysphagia at the early stage involves changes to food texture and teaching of swallowing techniques. In the later stages feeding can be through nasogastric tube (NGT) or gastrostomy insertion [64-66]. Current principles of care for dysphagia in MND are based on consensus and expert opinion rather than randomized controlled trials [67].

Guidelines of both the AAN and EFNS recommend the use of gastrostomy in MND $[19,20]$. Methods of gastrostomy insertion include percutaneous endoscopic gastrostomy (PEG), radiologically inserted gastrostomy (RIG), and Per-oral image-guided gastrostomy (PIG) $[68,69]$. In PEG which is the most commonly used method a wide bore-tube is fixed under endoscopic guidance after sedation to reduce the risk of migration and blockade $[70,71]$. The increased risk of aspiration due to sedation and its being unsuitable for patients with moderate to severe respiratory dysfunction are some of the drawbacks of PEG $[48,72]$.

RIG requires local anaesthesia for its insertion; thus it is observed to have higher success and lower complication rate [68]. It can be used even when FVC is $<50 \%$. The disadvantage of RIG is that it is not as securely fixed as PEG and the small tube used can easily be blocked. PIG is a new fluoroscopic technique that has a better long-term clinical outcome in terms of success and complication rates. It requires only local anaesthesia or minimal sedation, and the tube rarely blocks or migrates [70].

There is no evidence in literature regarding which insertion method is superior in any given circumstance [73]. The need for robust randomized prospective trials is encouraged by both AAN and EFNS $[19,64]$. Three recent studies [74-76] could not demonstrate any significant difference in survival between PEG and RIG. Another study observed significant difference $(P=0.004)$ between survival in PEG and RIG patients in a subgroup with respiratory failure [68]. The median survival after gastrostomy was $140 \%$ higher in the RIG group compared to PEG patients. It is believed that suggestions of PEG being better are just tentative conclusions. [77].

Home parenteral nutrition (HPN) using a central venous catheter is considered as an alternative to long-term nutritional support for MND patients with dysphagia when gastrostomy is contraindicated due to severe respiratory distress. Though it is more expensive than gastrostomy, recent evidence that HPN can be well tolerated and can improve nutritional status is patient with MND [78]. Hypercaloric enteric nutrition has been proposed as a factor that can improve survival because mild obesity is associated with improved survival [79]. Wills et al. [79] evaluated the safety and tolerability of high carbohydrate hypercaloric diet in patients with MND receiving enteric nutrition and observed that when compared to patients receiving isocaloric tube-fed diet or high fat hypercaloric diet, there was lower adverse effect or serious adverse event in the high-carbohydrate hypercaloric group. They were of the view that high carbohydrate hypercaloric enteric nutrition is safe and tolerable in patients with MND.

\subsubsection{Other Symptomatic Management}

Sialorrhoea. Excessive salivation is common in MND as bulbar dysfunction worsens and can be embarrassing or result in aspiration. Amitriptyline, Atropine, Botulin toxin type-B (BTX-B), and external irradiation of the salivary gland have all been tried in the control of sialorrhoea. A double-blind control trial BTX-B injected into the parotid and mandibular gland of 20 patients with refractory sialorrhoea achieved $82 \%$ reported improvement compared to $38 \%$ among those who received placebo at 2 months $(P<0.05)$ [80]. Costa et al. [81] also evaluated the efficacy and safety of BTX-B in the treatment of sialorrhoea in patients with a bulbar onset MND in an open-labeled prospective study that involved the injection of BTX-B into the parotid and submandibular glands. They observed that most patients reported a better 
quality of life while on treatment and a mean reduction of symptom severity of $70 \%$. The most commonly reported side effects include viscous saliva, local pain, chewing weakness, and respiratory infection.

Bronchial Secretion. Bulbar impairment results in poor clearance of tenacious sputum. Mucus accumulation is a poor prognostic factor in patients on NIV [82]. No RCT exists for any of the treatment approaches in MND. EFNS recommends the use of mucolytics such as $\mathrm{N}$-acetylcysteine when there is sufficient cough flow.

Pseudobulbar Affect. This is observed in up to 50\% of MND patients [83]. Yawning, weeping, and laughing are the characteristic presentation. Pseudobulbar affect has a negative impact on QOL. Small placebo controlled trials and case series have observed the effectiveness of selective serotonin reuptake inhibitors (SSRI) and tricyclic antidepressants in controlling this symptom $[84,85]$. Pioro et al. [86] evaluated the treatment of pseudobulbar affect in patients with multiple sclerosis and MND in a randomized-controlled trial using 30/10 mg and 20/10 mg Dextromethorphan plus ultralow-dose quinidine. They reported that dextromethorphan plus ultra-low-dose quinidine is effective in reducing the frequency and severity of symptoms and improving patients' quality of life especially at the dose of $30 / 10 \mathrm{mg}$ combination when compared with placebo. EFNS recommends Citalopram (SSRI) and Amitriptyline (TCA) for treatment of troublesome cases of pseudobulbar affect [20]. A fixed dose combination of dextromethorphan/quinidine $(30 \mathrm{mg} / 30 \mathrm{mg}$ ) is the recommended treatment option of AAN [87].

Cramps. It is usually troublesome particularly at night. A RCT failed to support the efficacy of tetracannabinoid in treating moderate to severe cramp [88]. A small openlabeled pilot study confirmed that levetiracetam is useful for treatment of cramps in MND patients [89]. Modalities such as massage, physical exercise, hydrotherapy, heated pools, and drugs like carbamazepine, diazepam, phenytoin, and verapamil have all been tried without any conclusive evidence. EFNS recommends levetiracetam, quinine sulfate, and physical therapies for management of cramp in MND.

Spasticity. Physical therapy is the main treatment modality for spasticity that has its usefulness established from randomized controlled trial in literature [20,90]. Physical therapy methods in use include therapeutic exercise, stretching, positioning, casting, and biofeedback. Other interventions with no controlled trial evidence include heat/cold therapy, hydrotherapy, ultrasound, electrical stimulation, and chemodenervation and rarely surgery can be used [20]. Intrathecal Baclofen is the drug of choice in intractable cases $[20,91]$. Drugs such as Dantrolene, Tetrazepam, and Tizanidine have not been tested in MND in clinical practice but are recommended by EFNS. Nonpharmacological treatment modalities should first be deployed before pharmacological interventions are introduced if symptoms do not improve. These drugs should be used with caution in MND patients as they can cause depression of respiration and worsening of weakness. Physical therapy can be combined with one or more of the antispasticity drugs [92].

Insomnia and Fatigue. Insomnia is common in the final stages of MND probably due to cramps, pain, and respiratory impairment [93]. Amitriptyline and Zolpidem are some of the medications used in practice without being tested. Fatigue is potentially debilitating and may be of central or peripheral origin. An open-labeled trial confirmed the effectiveness of Modafinil in the treatment of fatigue in MND [94, 95].

Cognitive Impairment. MND is associated with a frontotemporal type of dementia and it is associated with a negative impact on survival [96]. Cognitive impairment has been demonstrated in $20-50 \%$ of patients with MND. A number of screening instruments are available for assessing cognitive impairment in MND, but EFNS recommends the use of tools that can assesses verbal fluency as a major component of any test instrument [20].

Communication. It is important for effective social interactions. Subtle changes may be seen as word finding difficulties, spelling difficulty, and decreased verbal output. Language impairment results in difficulties in clinical management and decreases QOL of patients and caregivers [97]. EFNS recommends 3-6 monthly assessment; full neuropsychology test; and use of communication aids like computerized speech synthesizer [20].

Palliative Care. This is a holistic management of patients with terminal disease aimed at optimizing the QOL of patients and their caregivers. Palliative care in MND should ideally start at the point of diagnosis and continue throughout the entire history of the disease. It is needed at the different stages of the disease such as at the time of diagnosis to address issues relating to breaking of the bad news to patient and their caregivers; during crises points for example, introduction of NIV or PEG; and terminal stage when the patients' condition deteriorates. The application of the palliative care techniques should be organized to meet the need of individual patients as the reaction of patients and their families to the evolution of the disease varies between patients. It should focus on aspects of care such as physical (symptom control); psychological (effect of disease on patients); social (impact of disease on family and care-givers); and spiritual (questions bordering on meaning of life and the fear of dying). The approach should integrate both clinic and community-based care from onset of disease and continue even after the patient has died [11, 98]. EFNS guidelines [20] recommend early palliative care referral with discussion covering aspects of end-of-life, advance directive, and naming of health-care proxy.

Steinhansen et al. [99] evaluated a group of seriously ill patients, recently bereaved patient relatives, physicians, and other healthcare providers in a study to determine the factors considered to be important at end-of-life. All respondents agreed that naming a decision maker, maintaining one's dignity, having a care provider one can trust, to be pain free, having one's financial affairs in order, be free of shortness of breath and anxiety, to have a physician who is comfortable 
talking about death and knowing that one's family is prepared for their death among others are issues which are important for palliative care. They also largely accepted pain and symptom management as issues that palliative care should address.

\section{Areas Needing Further Research in MND}

Further research is needed in examining referral bias to MDC and other factors, which may influence effectiveness of MDC clinic outcomes such as frequency of visit. Biomarker for early diagnosis should be evaluated as this aids in research into DMT. Better evidence is still needed in the best parenteral feeding modality and the most optimal time of initiating/withdrawing it; impact of cough-assisting devices; nutritional management techniques on the QOL; evaluation of language dysfunction and its management treatment; the cost effectiveness of different treatment modalities; approach to the management of terminal care; and evidence for advance directives, impact of disease, and effect of disease on QOL of caregivers.

\section{Conclusion}

MND is a fatal syndrome with short disease course and low incidence. Scarcity of evidence for most of current treatment modalities requires further trials to standardize care for patients.

\section{Conflict of Interests}

The authors declare that there is no conflict of interests regarding the publication of this paper.

\section{References}

[1] G. Logroscino, B. J. Traynor, O. Hardiman et al., "Descriptive epidemiology of amyotrophic lateral sclerosis: new evidence and unsolved issues," Journal of Neurology, Neurosurgery and Psychiatry, vol. 79, no. 1, pp. 6-11, 2008.

[2] MNDA, Research Strategy 2006-2012, Motor Neuron Disease Association, Northampton, UK, 2007.

[3] M. R. Turner and A. Al-Chalabi, "Clinical phenotypes," in The Motor Neurone Disease Handbook, M. Kiernan, Ed., pp. 55-73, Australasian Medical Publishing Company Limited, Prymont, Australia, 2007.

[4] B. R. Brooks, "El Escorial World Federation of Neurology criteria for the diagnosis of amyotrophic lateral sclerosis," Journal of the Neurological Sciences, vol. 124, pp. 96-107, 1994.

[5] B. R. Brooks, R. G. Miller, M. Swash, and T. L. Munsat, "El Escorial revisited: revised criteria for the diagnosis of amyotrophic lateral sclerosis," Amyotrophic Lateral Sclerosis, vol. 1, no. 5, pp. 293-299, 2000.

[6] L. Forsgren, B. G. L. Almay, G. Holmgren, and S. Wall, "Epidemiology of motor neuron disease in Northern Sweden," Acta Neurologica Scandinavica, vol. 68, no. 1, pp. 20-29, 1983.

[7] F. Khan, L. Turner-Stokes, L. Ng, and T. Kilpatrick, "Multidisciplinary rehabilitation for adults with multiple sclerosis," Cochrane Database of Systematic Reviews, no. 2, Article ID CD006036, 2011.
[8] J. Greener and P. Langhorne, "Systematic reviews in rehabilitation for stroke: issues and approaches to addressing them," Clinical Rehabilitation, vol. 16, no. 1, pp. 69-74, 2002.

[9] L. Turner-Stokes, N. Sykes, E. Silbert, A. Khatri, L. Sutton, and E. Young, "From diagnosis to death: exploring the interface between neurology, rehabilitation and palliative care in the management of people with long term neurological conditions," Clinical Medicine, vol. 7, no. 2, pp. 129-136, 2007.

[10] O. Hardiman, "Multidisciplinary care in motor neurone disease," in The Motor Neurone Disease Handbook, M. Kiernan, Ed., Australasian Medical Publishing Company, Pyrmont, Australia, 2007.

[11] D. Oliver, "Palliative care for motor neurone disease," Practical Neurology, vol. 2, no. 2, pp. 68-79, 2002.

[12] L. Ng, F. Khan, and S. Mathers, "Multidisciplinary care for adults with amyotrophic lateral sclerosis or motor neuron disease," Cochrane Database of Systematic Reviews, no. 4, Article ID CD007425, 2009.

[13] B. J. Traynor, M. Alexander, B. Corr, E. Frost, and O. Hardiman, "Effect of a multidisciplinary amyotrophic lateral sclerosis (ALS) clinic on ALS survival: a population based study, 19962000," Journal of Neurology, Neurosurgery and Psychiatry, vol. 74, no. 9, pp. 1258-1261, 2003.

[14] J. P. van den Berg, S. Kalmijn, E. Lindeman et al., "Multidisciplinary ALS care improves quality of life in patients with ALS," Neurology, vol. 65, no. 8, pp. 1264-1267, 2005.

[15] I. van der Steen, J. P. van den Berg, E. Buskens, E. Lindeman, and L. H. van den Berg, "The costs of amyotrophic lateral sclerosis, according to type of care," Amyotrophic Lateral Sclerosis, vol. 10, no. 1, pp. 27-34, 2009.

[16] S. Zoccolella, E. Beghi, G. Palagano et al., "Riluzole and amyotrophic lateral sclerosis survival: a population-based study in southern Italy," European Journal of Neurology, vol. 14, no. 3, pp. 262-268, 2007.

[17] A. Chiò, E. Bottacchi, C. Buffa, R. Mutani, G. Mora, and PARALS, "Positive effects of tertiary centres for amyotrophic lateral sclerosis on outcome and use of hospital facilities," Journal of Neurology, Neurosurgery \& Psychiatry, vol. 77, no. 8, pp. 948-950, 2006.

[18] T. Aridegbe, R. Kandler, S. J. Walters, T. Walsh, P. J. Shaw, and C. J. McDermott, "The natural history of motor neuron disease: assessing the impact of specialist care," Amyotrophic Lateral Sclerosis and Frontotemporal Degeneration, vol. 14, no. 1, pp. 1319, 2013.

[19] R. G. Miller, C. E. Jackson, E. J. Kasarskis et al., "Practice parameter update: the care of the patient with amyotrophic lateral sclerosis: drug, nutritional, and respiratory therapies (an evidence-based review). Report of the quality standards subcommittee of the American academy of neurology," Neurology, vol. 73, no. 15, pp. 1218-1226, 2009.

[20] P. M. Andersen, S. Abrahams, G. D. Borasio et al., "EFNS guidelines on the clinical management of amyotrophic lateral sclerosis (MALS)-revised report of an EFNS task force," European Journal of Neurology, vol. 19, no. 3, pp. 360-375, 2012.

[21] P. J. Shaw, "Molecular and cellular pathways of neurodegeneration in motor neurone disease," Journal of Neurology, Neurosurgery \& Psychiatry, vol. 76, no. 6, pp. 1046-1057, 2005.

[22] M. Cozzolino, A. Ferri, and M. T. Carrì, "Amyotrophic lateral sclerosis: from current developments in the laboratory to clinical implications," Antioxidants \& Redox Signaling, vol. 10, no. 3, pp. 405-443, 2008. 
[23] L. C. Wijesekera and P. N. Leigh, "Amyotrophic lateral sclerosis," Orphanet Journal of Rare Diseases, vol. 4, no. 1, article 3, 2009.

[24] J. D. Rothstein, "Therapeutic horizons for amyotrophic lateral sclerosis," Current Opinion in Neurobiology, vol. 6, no. 5, pp. 679-687, 1996.

[25] G. Bensimon, L. Lacomblez, and V. Meininger, "A controlled trial of riluzole in amyotrophic lateral sclerosis," The New England Journal of Medicine, vol. 330, no. 9, pp. 585-591, 1994.

[26] L. Lacomblez, G. Bensimon, P. N. Leigh, P. Guillet, and V. Meininger, "Dose-ranging study of riluzole in amyotrophic lateral sclerosis," The Lancet, vol. 347, no. 9013, pp. 1425-1431, 1996.

[27] G. Bensimon, L. Lacomblez, J. C. Delumeau, R. Bejuit, P. Truffinet, and V. Meininger, "A study of riluzole in the treatment of advanced stage or elderly patients with amyotrophic lateral sclerosis," Journal of Neurology, vol. 249, no. 5, pp. 609-615, 2002.

[28] N. Yanagisawa, K. Tashiro, H. Tohgi et al., "Efficacy and safety of riluzole in patients with amyotrophic lateral sclerosis: doubleblind placebo controlled study in Japan," Igakuno Ayumi, vol. 182, pp. 851-866, 1997.

[29] R. G. Miller, J. D. Mitchell, and D. H. Moore, "Riluzole for amyotrophic lateral sclerosis (ALS)/motor neuron disease (MND)," Cochrane Database of Systematic Reviews, 2012.

[30] M. Graf, D. Ecker, R. Horowski et al., "High dose vitamin E therapy in amyotrophic lateral sclerosis as add-on therapy to riluzole: results of a placebo-controlled double-blind study," Journal of Neural Transmission, vol. 112, no. 5, pp. 649-660, 2005.

[31] V. Palma, V. Bresci, M. Polverino, L. Santoro, and G. Caruso, "An open study of riluzole versus riluzole plus gabapentin in amyotrophic lateral sclerosis," Journal of the Peripheral Nervous System, vol. 5, no. 1, pp. 46-47, 2000.

[32] P. Caroni, "Activity-sensitive signaling by muscle-derived insulin-like growth factors in the developing and regenerating neuromuscular system," Annals of the New York Academy of Sciences, vol. 692, pp. 209-222, 1993.

[33] N. T. Neff, D. Prevette, L. J. Houenou et al., "Insulin-like growth factors: putative muscle-derived trophic agents that promote motoneuron survival," Journal of Neurobiology, vol. 24, no. 12, pp. 1578-1588, 1993.

[34] M. Beauverd, J. D. Mitchell, J. H. J. Wokke, and G. D. Borasio, "Recombinant human insulin-like growth factor I (rhIGF-I) for the treatment of amyotrophic lateral sclerosis/motor neuron disease," Cochrane Database of Systematic Reviews, vol. 11, Article ID CD002064, 2012.

[35] P. Bongioanni, C. Reali, and V. Sogos, "Ciliary neurotrophic factor (CNTF) for amyotrophic lateral sclerosis/motor neuron disease," Cochrane Database of Systematic Reviews, no. 3, Article ID CD004302, 2004.

[36] R. W. Orrell, R. J. M. Lane, and M. Ross, "Antioxidant treatment for amyotrophic lateral sclerosis or motor neuron disease," The Cochrane Database of Systematic Reviews, no. 1, Article ID CD002829, 2007.

[37] M. E. Gurney, F. B. Cutting, P. Zhai et al., "Benefit of vitamin E, riluzole, and gabapentin in a transgenic model of familial amyotrophic lateral sclerosis," Annals of Neurology, vol. 39, no. 2, pp. 147-157, 1996.

[38] J. Knoll, "The pharmacology of selegiline ((-)deprenyl). New aspects," Acta Neurologica Scandinavica, vol. 80, no. 126, pp. 8391, 1989.
[39] E. S. Louwerse, G. J. Weverling, P. M. Bossuyt, F. E. Meyjes, and J. M. de Jong, "Randomized, double-blind, controlled trial of acetylcysteine in amyotrophic lateral sclerosis," Archives of Neurology, vol. 52, no. 6, pp. 559-564, 1995.

[40] A. Eisen and C. Krieger, Amyotrophic Lateral Sclerosis: A Synthesis of Research and Clinical Practice, Cambridge University Press, Cambridge, UK, Edited by A. Eisen and C. Krieger, 1998.

[41] M. K. Rafi, A. R. Proctor, C. J. McDermott, and P. J. Shaw, "Respiratory management of motor neurone disease: a review of current practice and new developments," Practical Neurology, vol. 12, no. 3, pp. 166-176, 2012.

[42] S. C. Bourke, P. J. Shaw, and G. J. Gibson, "Respiratory function vs sleep-disordered breathing as predictors of QOL in ALS," Neurology, vol. 57, no. 11, pp. 2040-2044, 2001.

[43] N. Lechtzin, C. M. Wiener, D. M. Shade, L. Clawson, and G. B. Diette, "Spirometry in the supine position improves the detection of diaphragmatic weakness in patients with amyotrophic lateral sclerosis," Chest, vol. 121, no. 2, pp. 436-442, 2002.

[44] A. Radunovic, D. Annane, M. K. Rafiq, and N. Mustfa, "Mechanical ventilation for amyotrophic lateral sclerosis/motor neuron disease," Cochrane Database of Systematic Reviews, no. 3, Article ID CD004427, 2013.

[45] S. C. Bourke, R. E. Bullock, T. L. Williams, P. J. Shaw, and G. J. Gibson, "Noninvasive ventilation in ALS: indications and effect on quality of life," Neurology, vol. 61, no. 2, pp. 171-177, 2003.

[46] S. C. Bourke, M. Tomlinson, T. L. Williams, R. E. Bullock, P. J. Shaw, and G. J. Gibson, "Effects of non-invasive ventilation on survival and quality of life in patients with amyotrophic lateral sclerosis: a randomised controlled trial," The Lancet Neurology, vol. 5, no. 2, pp. 140-147, 2006.

[47] A. Radunovic, D. Annane, K. Jewitt, and N. Mustfa, "Mechanical ventilation for amyotrophic lateral sclerosis/motor neuron disease," Cochrane Database of Systematic Reviews, no. 7, Article ID CD004427, 2009.

[48] K. A. Kleopa, M. Sherman, B. Neal, G. J. Romano, and T. Heiman-Patterson, "Bipap improves survival and rate of pulmonary function decline in patients with ALS," Journal of the Neurological Sciences, vol. 164, no. 1, pp. 82-88, 1999.

[49] A. Pinto, J. P. Almeida, S. Pinto, J. Pereira, A. G. Oliveira, and M. De Carvalho, "Home telemonitoring of non-invasive ventilation decreases healthcare utilisation in a prospective controlled trial of patients with amyotrophic lateral sclerosis," Journal of Neurology, Neurosurgery and Psychiatry, vol. 81, no. 11, pp. 1238-1242, 2010.

[50] A. Vianello, G. Arcaro, A. Palmieri et al., "Survival and quality of life after tracheostomy for acute respiratory failure in patients with amyotrophic lateral sclerosis," Journal of Critical Care, vol. 26, no. 3, pp. 329.e7-329.e14, 2011.

[51] L. H. Goldstein, L. Atkins, and P. N. Leigh, "Correlates of quality of life in people with motor neuron disease (MND)," Amyotrophic Lateral Sclerosis and Other Motor Neuron Disorders, vol. 3, no. 3, pp. 123-129, 2002.

[52] P. A. Cazzolli and E. A. Oppenheimer, "Home mechanical ventilation for amyotrophic lateral sclerosis: nasal compared to tracheostomy-intermittent positive pressure ventilation," Journal of the Neurological Sciences, vol. 139, pp. 123-128, 1996.

[53] A. Kawata, K. Mizoguchi, and H. Hayashi, "A nationwide survey of ALS patients on trachoestomy positive pressure ventilation (TPPV) who developed a totally locked-in state (TLS) in Japan," Rinsho shinkeigaku, vol. 48, no. 7, pp. 476-480, 2008. 
[54] D. S. Tulsky and M. Rosenthal, "Measurement of quality of life in rehabilitation medicine: emerging issues," Archives of Physical Medicine and Rehabilitation, vol. 84, no. 4, pp. S1-S2, 2003.

[55] S. Hadjikoutis, C. M. Wiles, and R. Eccles, "Cough in motor neuron disease: a review of mechanisms," QJM, vol. 92, no. 9, pp. 487-494, 1999.

[56] J. R. Bach, "Amyotrophic lateral sclerosis: prolongation of life by noninvasive respiratory aids," Chest, vol. 122, no. 1, pp. 92-98, 2002.

[57] J. R. Bach, Y. Ishikawa, and H. Kim, "Prevention of pulmonary morbidity for patients with Duchenne muscular dystrophy," Chest, vol. 112, no. 4, pp. 1024-1028, 1997.

[58] M. F. Brito, G. A. Moreira, M. Pradella-Hallinan, and S. Tufik, "Air stacking and chest compression increase peak cough flow in patients with Duchenne muscular dystrophy," Jornal Brasileiro de Pneumologia, vol. 35, no. 10, pp. 973-979, 2009.

[59] M. Toussaint, L. J. Boitano, V. Gathot, M. Steens, and P. Soudon, "Limits of effective cough-augmentation techniques in patients with neuromuscular disease," Respiratory Care, vol. 54, no. 3, pp. 359-366, 2009.

[60] T. Hughes, "Neurology of swallowing and oral feeding disorders: assessment and management," Journal of Neurology, Neurosurgery \& Psychiatry, vol. 74, supplement 3, pp. iii48-iii52, 2003.

[61] D. Kidney, M. Alexander, B. Corr, O. O’Toole, and O. Hardiman, "Oropharyngeal dysphagia in amyotrophic lateral sclerosis: neurological and dysphagia specific rating scales," Amyotrophic Lateral Sclerosis and Other Motor Neuron Disorders, vol. 5, no. 3, pp. 150-153, 2004.

[62] J. Skelton, "Nursing role in the multidisciplinary management of motor neurone disease," British Journal of Nursing, vol. 14, no. 1, pp. 20-24, 2005.

[63] J. C. Desport, P. M. Preux, C. T. Truong, L. Courat, J. M. Vallat, and P. Couratier, "Nutritional assessment and survival in ALS patients," Amyotrophic Lateral Sclerosis and Other Motor Neuron Disorders, vol. 1, no. 2, pp. 91-96, 2000.

[64] P. M. Andersen, G. D. Borasio, R. Dengler et al., "EFNS task force on management of amyotrophic lateral sclerosis: guidelines for diagnosing and clinical care of patients and relatives," European Journal of Neurology, vol. 12, no. 12, pp. 921938, 2005.

[65] P. H. Gordon and H. Mitsumoto, "Symptomatic therapy and palliative aspects of clinical care," in Handbook of Clinical Neurology, A. A. Eisen and P. J. Shaw, Eds., pp. 389-424, Elsevier, 2007.

[66] A. Radunović, H. Mitsumoto, and P. N. Leigh, "Clinical care of patients with amyotrophic lateral sclerosis," Lancet Neurology, vol. 6, no. 10, pp. 913-925, 2007.

[67] S. E. Langmore, E. J. Kasarskis, M. L. Manca, and R. K. Olney, "Enteral tube feeding for amyotrophic lateral sclerosis/motor neuron disease," Cochrane Database of Systematic Reviews, no. 4, Article ID CD004030, 2006.

[68] A. Chiò, R. Galletti, C. Finocchiaro et al., "Percutaneous radiological gastrostomy: a safe and effective method of nutritional tube placement in advanced ALS," Journal of Neurology, Neurosurgery and Psychiatry, vol. 75, no. 4, pp. 645-647, 2004.

[69] G. Chavada, A. El-Nayal, F. Lee et al., "Evaluation of two different methods for per-oral gastrostomy tube placement in patients with motor neuron disease (MND): PIG versus PEG procedures," Amyotrophic Lateral Sclerosis, vol. 11, no. 6, pp. 531536, 2010.
[70] H.-U. Laasch, L. Wilbraham, K. Bullen et al., "Gastrostomy insertion: comparing the options-PEG, RIG or PIG?" Clinical Radiology, vol. 58, no. 5, pp. 398-405, 2003.

[71] P. N. Leigh, S. Abrahams, A. Al-Chalabi et al., "The management of motor neurone disease," Journal of Neurology, Neurosurgery \& Psychiatry, vol. 74, supplement 4, pp. iv32-iv47, 2003.

[72] R. A. Lyall, N. Donaldson, M. I. Polkey, P. N. Leigh, and J. Moxham, "Respiratory muscle strength and ventilatory failure in amyotrophic lateral sclerosis," Brain, vol. 124, no. 10, pp. 2000-2013, 2001.

[73] J. Rosenfeld and A. Ellis, "Nutrition and dietary supplements in motor neuron disease," Physical Medicine and Rehabilitation Clinics of North America, vol. 19, no. 3, pp. 573-589, 2008.

[74] F. J. Thornton, T. Fotheringham, M. Alexander, O. Hardiman, F. P. McGrath, and M. J. Lee, "Amyotrophic lateral sclerosis: enteral nutrition provision-endoscopic or radiologic gastrostomy?" Radiology, vol. 224, no. 3, pp. 713-717, 2002.

[75] A. S. Shaw, M.-A. Ampong, A. Rio et al., "Survival of patients with ALS following institution of enteral feeding is related to pre-procedure oximetry: a retrospective review of 98 patients in a single centre," Amyotrophic Lateral Sclerosis, vol. 7, no. 1, pp. 16-21, 2006.

[76] J.-C. Desport, T. Mabrouk, P. Bouillet, A. Perna, P.-M. Preux, and P. Couratier, "Complications and survival following radiologically and endoscopically-guided gastronomy in patients with amyotrophic lateral sclerosis," Amyotrophic Lateral Sclerosis, vol. 6, no. 2, pp. 88-93, 2005.

[77] H. D. Katzberg and M. Benatar, "Enteral tube feeding for amyotrophic lateral sclerosis/motor neuron disease," Cochrane Database of Systematic Reviews, vol. 1, Article ID CD004030, 2011.

[78] A. Verschueren, A. Monnier, S. Attarian, D. Lardillier, and J. Pouget, "Enteral and parenteral nutrition in the later stages of ALS: an observational study," Amyotrophic Lateral Sclerosis, vol. 10, no. 1, pp. 42-46, 2009.

[79] A.-M. Wills, J. Hubbard, E. A. Macklin et al., "Hypercaloric enteral nutrition in patients with amyotrophic lateral sclerosis: a randomised, double-blind, placebo-controlled phase 2 trial," The Lancet, vol. 383, no. 9934, pp. 2065-2072, 2014.

[80] C. E. Jackson, G. Gronseth, J. Rosenfeld et al., "Randomized double-blind study of botulinum toxin type B for sialorrhea in ALS patients," Muscle \& Nerve, vol. 39, no. 2, pp. 137-143, 2009.

[81] J. Costa, M. L. Rocha, J. Ferreira, T. Evangelista, M. Coelho, and M. De Carvalho, "Botulinum toxin type-B improves sialorrhea and quality of life in bulbaronset amyotrophic lateral sclerosis," Journal of Neurology, vol. 255, no. 4, pp. 545-550, 2008.

[82] S. Peysson, N. Vandenberghe, F. Philit et al., "Factors predicting survival following noninvasive ventilation in amyotrophic lateral sclerosis," European Neurology, vol. 59, no. 3-4, pp. 164-171, 2008.

[83] J. P. Gallagher, "Pathologic laughter and crying in ALS: a search for their origin," Acta Neurologica Scandinavica, vol. 80, no. 2, pp. 114-117, 1989.

[84] A. Szczudlik, A. Słowik, and B. Tomik, "The effect of amitriptyline on the pathological crying and other pseudobulbar signs," Neurologia i Neurochirurgia Polska, vol. 29, no. 5, pp. 663-674, 1995.

[85] S. Iannaccone and L. Ferini-Strambi, "Pharmacologic treatment of emotional lability," Clinical Neuropharmacology, vol. 19, no. 6, pp. 532-535, 1996. 
[86] E. P. Pioro, B. R. Brooks, J. Cummings et al., "Dextromethorphan plus ultra low-dose quinidine reduces pseudobulbar affect," Annals of Neurology, vol. 68, no. 5, pp. 693-702, 2010.

[87] R. G. Miller, C. E. Jackson, E. J. Kasarskis et al., "Practice parameter update: the care of the patient with amyotrophic lateral sclerosis: drug, nutritional, and respiratory therapies (an evidence-based review): report of the quality standards subcommittee of the American academy of neurology," Neurology, vol. 73, no. 15, pp. 1218-1226, 2009.

[88] R. S. Bedlack, D. M. Pastula, J. Hawes, and D. Heydt, "Openlabel pilot trial of levetiracetam for cramps and spasticity in patients with motor neuron disease," Amyotrophic Lateral Sclerosis, vol. 10, no. 4, pp. 210-215, 2009.

[89] H. D. Katzberg, A. H. Khan, and Y. T. So, "Assessment: symptomatic treatment for muscle cramps (an evidence-based review): report of the therapeutics and technology assessment subcommittee of the American Academy of Neurology," Neurology, vol. 74, no. 8, pp. 691-696, 2010.

[90] V. E. Drory, E. Goltsman, J. Goldman Reznik, A. Mosek, and A. D. Korczyn, "The value of muscle exercise in patients with amyotrophic lateral sclerosis," Journal of the Neurological Sciences, vol. 191, no. 1-2, pp. 133-137, 2001.

[91] S. McClelland III, F. A. Bethoux, N. M. Boulis et al., "Intrathecal baclofen for spasticity-related pain in amyotrophic lateral sclerosis: efficacy and factors associated with pain relief," Muscle \& Nerve, vol. 37, no. 3, pp. 396-398, 2008.

[92] G. T. Carter and R. G. Miller, "Comprehensive management of amyotrophic lateral sclerosis," Physical Medicine and Rehabilitation Clinics of North America, vol. 9, no. 1, pp. 271-284, 1998.

[93] J.-S. Lou, "Fatigue in amyotrophic lateral sclerosis," Physical Medicine and Rehabilitation Clinics of North America, vol. 19, no. 3, pp. 533-543, 2008.

[94] G. T. Carter, M. D. Weiss, J.-S. Lou et al., "Modafinil to treat fatigue in amyotrophic lateral sclerosis: an open label pilot study," American Journal of Hospice and Palliative Medicine, vol. 22, no. 1, pp. 55-59, 2005.

[95] J. G. Rabkin, P. H. Gordon, M. Mcelhiney, R. Rabkin, S. Chew, and H. Mitsumoto, "Modafinil treatment of fatigue in patients with ALS: a placebo-controlled study," Muscle and Nerve, vol. 39, no. 3, pp. 297-303, 2009.

[96] P. H. Gordon, B. Cheng, I. B. Katz et al., "The natural history of primary lateral sclerosis," Neurology, vol. 66, no. 5, pp. 647-653, 2006.

[97] M. Cobble, "Language impairment in motor neurone disease," Journal of the Neurological Sciences, vol. 160, no. 1, pp. S47-S52, 1998.

[98] G. D. Borasio, R. Voltz, and R. G. Miller, "Palliative care in amyotroph-ic lateral sclerosis," Neurologic Clinics, vol. 19, no. 4, pp. 829-847, 2001.

[99] K. E. Steinhauser, N. A. Christakis, E. C. Clipp, M. McNeilly, L. McIntyre, and J. A. Tulsky, "Factors considered important at the end of life by patients, family, physicians, and other care providers," Journal of the American Medical Association, vol. 284, no. 19, pp. 2476-2482, 2000.

[100] D. R. Rosen, T. Siddique, D. Patterson et al., "Mutations in $\mathrm{Cu} / \mathrm{Zn}$ superoxide dismutase gene are associated with familial amyotrophic lateral sclerosis," Nature, vol. 362, no. 6415, pp. 5962, 1993.

[101] A. Yokoseki, A. Shiga, C.-F. Tan et al., "TDP-43 mutation in familial amyotrophic lateral sclerosis," Annals of Neurology, vol. 63, no. 4, pp. 538-542, 2008.
[102] J. Sreedharan, I. P. Blair, V. B. Tripathi et al., "TDP-43 mutations in familial and sporadic amyotrophic lateral sclerosis," Science, vol. 319, no. 5870, pp. 1668-1672, 2008.

[103] E. Kabashi, P. N. Valdmanis, P. Dion et al., “TARDBP mutations in individuals with sporadic and familial amyotrophic lateral sclerosis," Nature Genetics, vol. 40, no. 5, pp. 572-574, 2008.

[104] S. Hadano, C. K. Hand, H. Osuga et al., "A gene encoding a putative GTPase regulator is mutated in familial amyotrophic lateral sclerosis 2," Nature Genetics, vol. 29, no. 2, pp. 166-173, 2001.

[105] Y. Yang, A. Hentati, H. X. Deng et al., "The gene encoding alsin, a protein with three guanine-nucleotide exchange factor domains, is mutated in a form of recessive amyotrophic lateral sclerosis," Nature Genetics, vol. 29, no. 2, pp. 160-165, 2001.

[106] Y.-Z. Chen, C. L. Bennett, H. M. Huynh et al., "DNA/RNA helicase gene mutations in a form of juvenile amyotrophic lateral sclerosis (ALS4)," The American Journal of Human Genetics, vol. 74, no. 6, pp. 1128-1135, 2004.

[107] A. L. Nishimura, M. Mitne-Neto, H. C. A. Silva et al., "A mutation in the vesicle-trafficking protein VAPB causes lateonset spinal muscular atrophy and amyotrophic lateral sclerosis," American Journal of Human Genetics, vol. 75, no. 5, pp. 822831, 2004.

[108] M. J. Greenway, M. D. Alexander, S. Ennis et al., "A novel candidate region for ALS on chromosome 14q11.2," Neurology, vol. 63, no. 10, pp. 1936-1938, 2004.

[109] M. J. Greenway, P. M. Andersen, G. Russ et al., "ANG mutations segregate with familial and 'sporadic' amyotrophic lateral sclerosis," Nature Genetics, vol. 38, no. 4, pp. 411-413, 2006.

[110] I. Puls, C. Jonnakuty, B. H. LaMonte et al., "Mutant dynactin in motor neuron disease," Nature Genetics, vol. 33, no. 4, pp. 455456, 2003.

[111] C. Münch, R. Sedlmeier, T. Meyer et al., "Point mutations of the p150 subunit of dynactin (DCTN1) gene in ALS," Neurology, vol. 63, no. 4, pp. 724-726, 2004.

[112] A. Al-Chalabi, Z. E. Enayat, M. C. Bakker et al., "Association of apolipoprotein E $\varepsilon 4$ allele with bulbar-onset motor neuron disease," The Lancet, vol. 347, no. 8995, pp. 159-160, 1996.

[113] T. Meyer, A. Fromm, C. Münch et al., "The RNA of the glutamate transporter EAAT2 is variably spliced in amyotrophic lateral sclerosis and normal individuals," Journal of the Neurological Sciences, vol. 170, no. 1, pp. 45-50, 1999.

[114] D. Trotti, M. Aoki, P. Pasinelli et al., "Amyotrophic lateral sclerosis-linked glutamate transporter mutant has impaired glutamate clearance capacity," The Journal of Biological Chemistry, vol. 276, no. 1, pp. 576-582, 2001.

[115] D. Lambrechts, E. Storkebaum, M. Morimoto et al., "VEGF is a modifier of amyotrophic lateral sclerosis in mice and humans and protects motoneurons against ischemic death," Nature Genetics, vol. 34, no. 4, pp. 383-394, 2003.

[116] P. Pasinelli and R. H. Brown, "Molecular biology of amyotrophic lateral sclerosis: insights from genetics," Nature Reviews Neuroscience, vol. 7, no. 9, pp. 710-723, 2006.

[117] L. Siklós, J. Engelhardt, Y. Harati, R. G. Smith, F. Joó, and S. H. Appel, "Ultrastructural evidence for altered calcium in motor nerve terminals in amyotrophic lateral sclerosis," Annals of Neurology, vol. 39, no. 2, pp. 203-216, 1996.

[118] F. R. Wiedemann, K. Winkler, A. V. Kuznetsov et al., "Impairment of mitochondrial function in skeletal muscle of patients with amyotrophic lateral sclerosis," Journal of the Neurological Sciences, vol. 156, no. 1, pp. 65-72, 1998. 
[119] T. L. Williamson and D. W. Cleveland, "Slowing of axonal transport is a very early event in the toxicity of ALS-linked SOD1 mutants to motor neurons," Nature Neuroscience, vol. 2, no. 1, pp. 50-56, 1999.

[120] T. Murakami, I. Nagano, T. Hayashi et al., "Impaired retrograde axonal transport of adenovirus-mediated E. coli LacZ gene in the mice carrying mutant SOD1 gene," Neuroscience Letters, vol. 308, no. 3, pp. 149-152, 2001.

[121] K. J. De Vos, A. J. Grierson, S. Ackerley, and C. C. J. Miller, "Role of axonal transport in neurodegenerative diseases," Annual Review of Neuroscience, vol. 31, pp. 151-173, 2008.

[122] S. Carpenter, "Proximal axonal enlargement in motor neuron disease," Neurology, vol. 18, no. 9, pp. 841-851, 1968.

[123] A. Hirano, I. Nakano, L. T. Kurland, D. W. Mulder, P. W. Holley, and G. Saccomanno, "Fine structural study of neurofibrillary changes in a family with amyotrophic lateral sclerosis," Journal of Neuropathology and Experimental Neurology, vol. 43, no. 5, pp. 471-480, 1984.

[124] P. Anand, A. Parrett, J. Martin et al., "Regional changes of ciliary neurotrophic factor and nerve growth factor levels in post mortem spinal cord and cerebral cortex from patients with motor disease," Nature Medicine, vol. 1, no. 2, pp. 168-172, 1995.

[125] J. L. Elliott and W. D. Snider, "Motor neuron growth factors," Neurology, vol. 47, no. 4, supplement 2, pp. S47-S53, 1996.

[126] R. W. Oppenheim, "Neurotrophic survival molecules for motoneurons: an embarrassment of riches," Neuron, vol. 17, no. 2, pp. 195-197, 1996.

[127] C. Guégan and S. Przedborski, "Programmed cell death in amyotrophic lateral sclerosis," Journal of Clinical Investigation, vol. 111, no. 2, pp. 153-161, 2003.

[128] P. Pasinelli, D. R. Borchelt, M. K. Houseweart, D. W. Cleveland, and R. H. Brown Jr., "Caspase-1 is activated in neural cells and tissue with amyotrophic lateral sclerosis-associated mutations in copper-zinc superoxide dismutase," Proceedings of the National Academy of Sciences of the United States of America, vol. 95, no. 26, pp. 15763-15768, 1998.

[129] P. Pasinelli, M. K. Houseweart, R. H. Brown Jr., and D. W. Cleveland, "Caspase-1 and -3 are sequentially activated in motor neuron death in $\mathrm{Cu}, \mathrm{Zn}$ superoxide dismutase-mediated familial amyotrophic lateral sclerosis," Proceedings of the National Academy of Sciences of the United States of America, vol. 97, no. 25, pp. 13901-13906, 2000. 


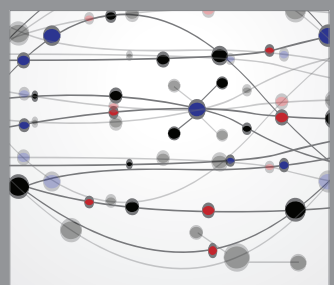

The Scientific World Journal
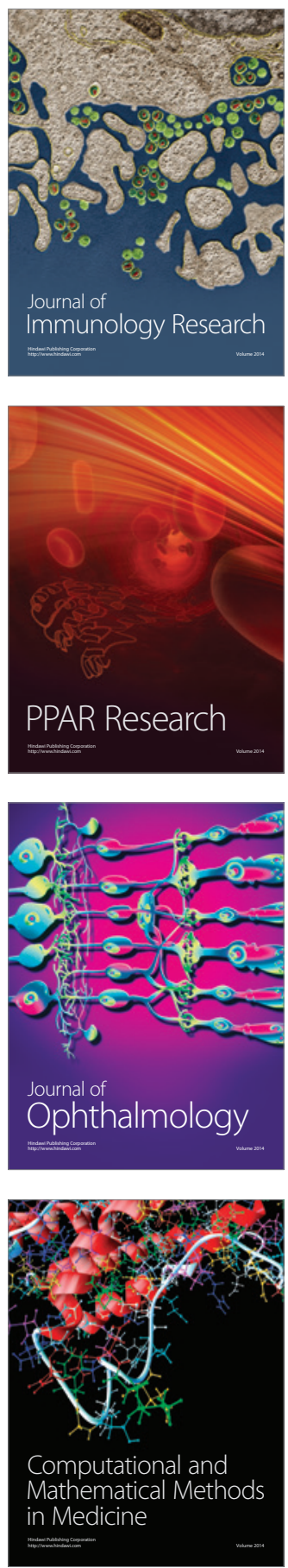

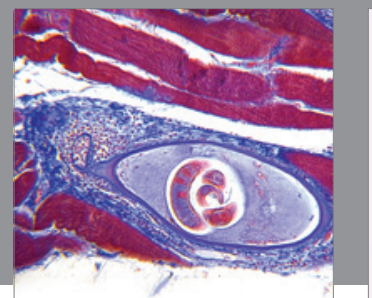

Gastroenterology

Research and Practice
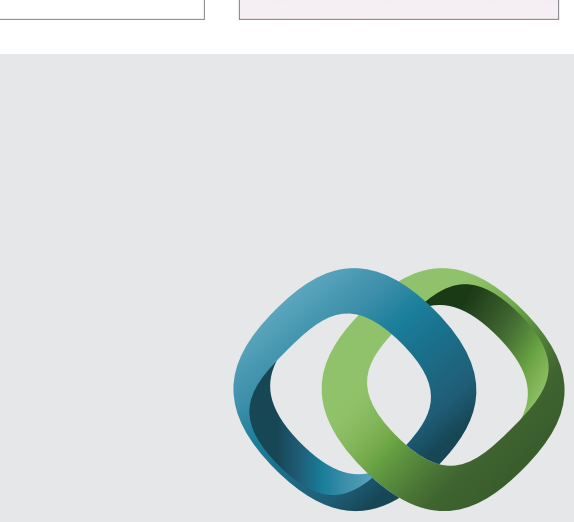

\section{Hindawi}

Submit your manuscripts at

http://www.hindawi.com
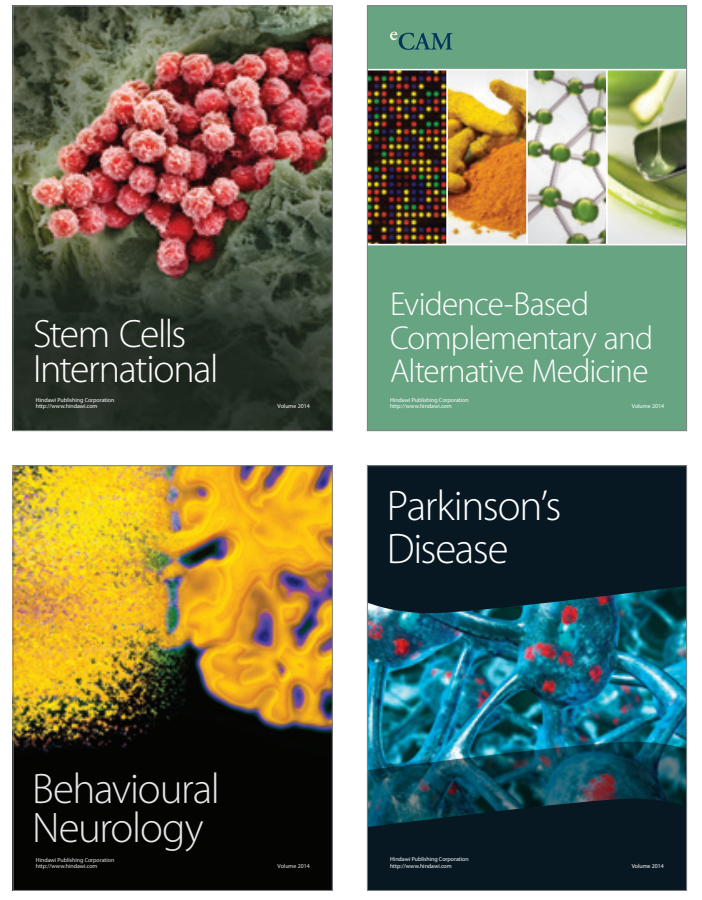
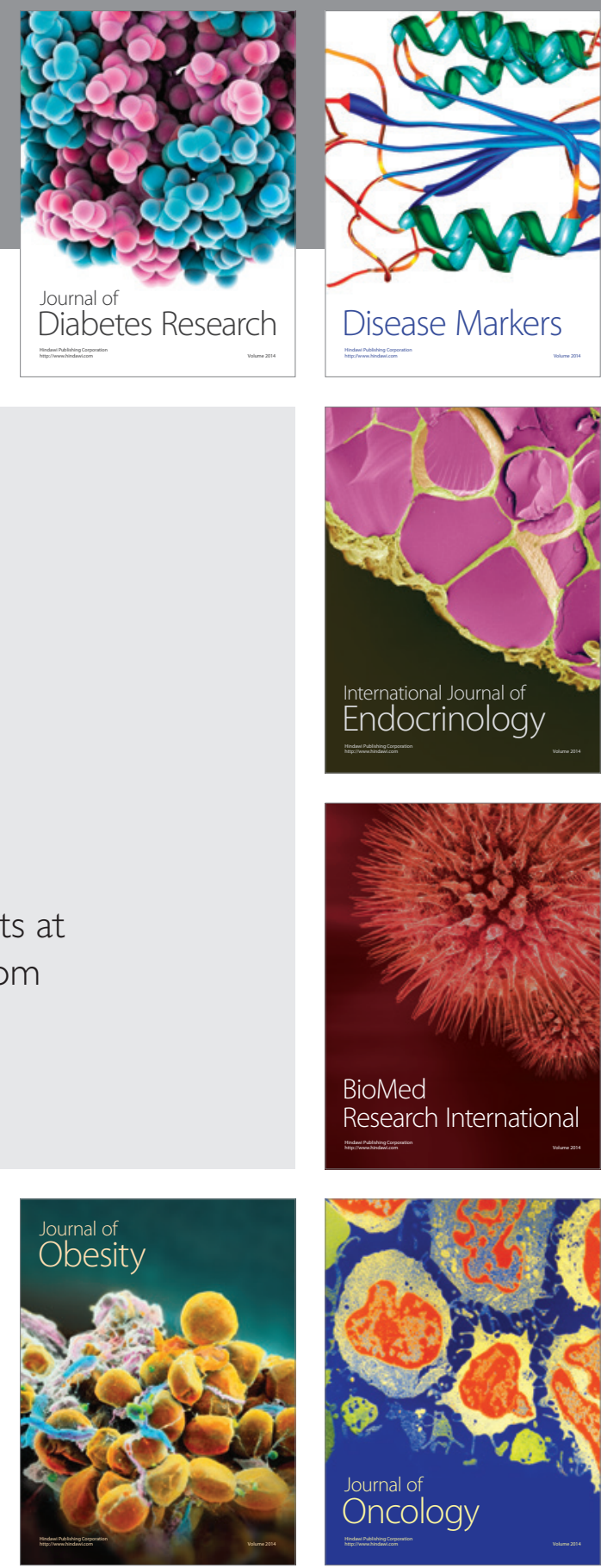

Disease Markers
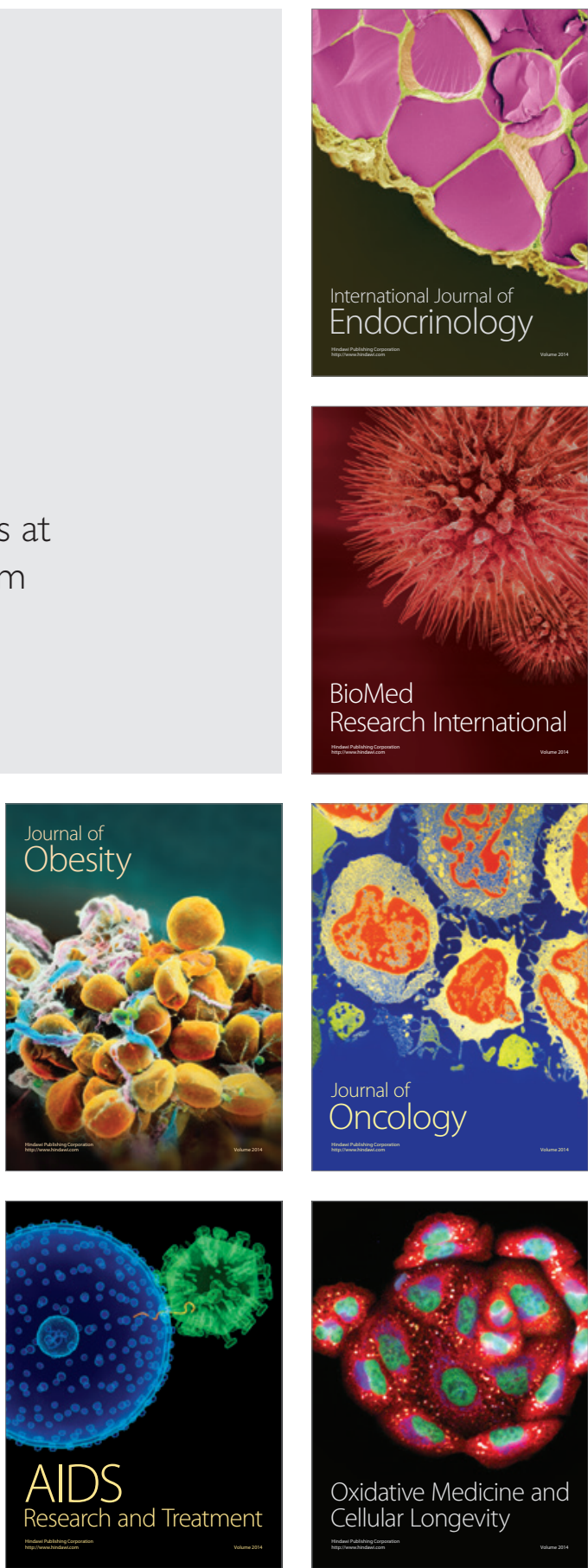